\title{
Prevalence and Adverse Effects of Maternal Obesity among Women Attending Antenatal Care Clinics at a Metropolitan Hospital in Southern Ghana
}

\author{
Diallo Abdoul Azize*, Oppong Miriam, Mouhajer Mohammed, Ken-Amoah Sebastian, \\ Agbeno Kofi Evans
}

Department of Obstetrics and Gynaecology, School of Medical Sciences, University of Cape Coast, Cape Coast, Ghana Email: *diallo.azize@uccsms.edu.gh

How to cite this paper: Azize, D.A., Miriam, O., Mohammed, M., Sebastian, K.-A. and Evans, A.K. (2021) Prevalence and Adverse Effects of Maternal Obesity among Women Attending Antenatal Care Clinics at a Metropolitan Hospital in Southern Ghana. Open Journal of Obstetrics and Gynecology, 11, 1629-1638.

https://doi.org/10.4236/ojog.2021.1111152

Received: October 1, 2021

Accepted: November 23, 2021

Published: November 26, 2021

Copyright $\odot 2021$ by author(s) and Scientific Research Publishing Inc. This work is licensed under the Creative Commons Attribution International License (CC BY 4.0).

http://creativecommons.org/licenses/by/4.0/

\begin{abstract}
Background: Maternal obesity and its associated health complications increase; however, area-specific data is lacking in Ghana. We attempted to assess the prevalence and adverse effects of maternal obesity in Ghana. Methods: Study population were women booking to, and gave birth to infants in Cape Coast Metropolitan Hospital, Ghana, during February 2018 to January $2019(\mathrm{n}=510)$. Body mass index (BMI) during the first trimester was identified and analyzed in relation with outcomes/complications. Results: Incidence of maternal obesity (overweight/obese, $\mathrm{BMI} \geq 25$ ) was $37.3 \%$. Of them, $34.4 \%$ had maternal complications such as postpartum haemorrhage, foetal distress, and cephalo-pelvic disproportion (in this order). The caesarian rate was $20.5 \%$. Among the non obese women only $20 \%$ had maternal complications and the caesarian section rate was $16.2 \%$. Obesity was positively correlated with maternal age and parity but was not with low socio-economic status. Obese women were more likely to have obstetric complications. Conclusions: Obese women were more likely to suffer obstetric complications and to have cesarean. Although present data was a confirmation of the existing data in other parts of the world, we believe that these data may be useful in making area-specific health policy.
\end{abstract}

\section{Keywords}

Cape Coast, Body Mass Index, Maternal Obesity, Obstetric Complications

\section{Introduction}

According to the World Health Organization, overweight and obesity are de- 
fined as abnormal or excessive fat accumulation that may impair health. Body mass index (BMI) is a simple index of weight-for-height that is commonly used to classify overweight and obesity in adults. It is defined as a person's weight in kilograms divided by the square of his height in meters $\left(\mathrm{kg} / \mathrm{m}^{2}\right)[1]$.

Obesity is a growing public health hazard worldwide. The proportion of global adult women with overweight increased from $29.8 \%$ (29.3\% - 30.2\%) in 1980 to $38.0 \%(37.5 \%-38.5 \%)$ in 2013 , and the increasing trend was observed in both high income and middle income countries [2].

Data from Pregnancy Risk Assessment Monitoring System (PRAMS), an ongoing population-survey has shown that the prevalence of pre-pregnancy obesity has increased by $69 \%$ over a 10 -year period, from $13 \%$ in $1993-1994$ to $22 \%$ in 2002-2003 [3].

Maternal overweight and obesity are associated with socio-demographic, lifestyle, and genetic factors and with increased risks of adverse maternal, fetal and childhood outcomes [4]. Lower educational level, lower household income and multiparity were risk factors implicated in maternal overweight and obesity [4]. Numerous researches, studies and theories have shown evidence suggesting that obese pregnant women are at greater risk of a number of maternal and fetal complications of pregnancy, including pre-eclampsia, caesarean section, antepartum intrauterine death, induction of labour and anaesthetic complications [5].

A study on Brazilian women of reproductive age using multiple obesity markers (body mass index (BMI), waist circumference (WC) and waist-to-height ratio (WHR)) found that the three markers are strongly and positively associated with spontaneous abortion and stillbirth occurrences [6].

There is little data on studies relating to maternal obesity and its associated complications in Africa and particularly Ghana and studies performed outside of Africa are resorted to, which might not have clearly reflected the issue from the African continent.

This research was conducted to assess the prevalence of obesity among pregnant women at a metropolitan hospital in southern Ghana, and how the obesity affected their pregnancy journeys and that of their babies during the pregnancy period and after delivery.

\section{Patients and Methods}

\subsection{Study Design}

A cross sectional survey with both prospective and retrospective data collection was carried out over a period of 12 consecutive months (including recruitment and follow up) from February 2018 to January 2019.

\subsection{Population}

The target population was pregnant women who attended the antenatal care clinics at the Cape Coast Metropolitan Hospital and had subsequent visits till the final outcome of their pregnancies. 
The data was obtained from the client's antenatal book and the records of the Antenatal clinic, obstetrics emergency and delivery suite records of the Cape Coast Metropolitan Hospital, located in the Central Regional capital of Ghana. Inclusion criteria:

- All pregnant women, who attended for antenatal services at the Cape Coast Metropolitan Hospital during the study period and with a recorded body mass index during the first trimester of pregnancy.

Exclusion criteria:

- The pregnant women who could not have their subsequent antenatal visits and those who could not have their delivery at the Cape Coast Metropolitan Hospital.

Maternal overweight and obesity was defined using a cut point of a Body Mass Index (BMI) more or equal to $25\left(\mathrm{in} \mathrm{kg} / \mathrm{m}^{2}\right)$ estimated in the first trimester of pregnancy.

\subsection{Sample and Sampling Technique}

Purposive total sampling was performed in recruiting our study sample. All pregnant women who met the inclusion criteria were surveyed.

\subsection{Data Collection Instrument}

A structured predesigned questionnaire was used in data collection. The questionnaire comprised items to collect socio-demographic, medical and obstetric history, BMI, events during pregnancy and outcomes.

\subsection{Statistical Analysis}

Data was coded and entered with Statistical Package for Social Sciences (SPSS) version 21 and later imported with STATA/IC version 15 (StataCorp LLC, Texas 77845 , USA) for management and analysis. Descriptive indices such as proportions (frequencies and prevalence) and mean (standard deviation) were used to summarize mothers' socio-demographic characteristics and maternal factors. One-way ANOVA test and t-test were used to determine whether mean body mass index (BMI) differ between the levels of socio-demographic characteristics and maternal factors, and complications. Further, a simple linear regression was performed to assess whether maternal obesity was associated with socio-demographic characteristics, maternal factors, and complications. All associations were considered at $95 \%$ confidence interval (CI) and 5\% level of significance. The results were presented in tables and charts.

The independent variable was Body Mass Index (BMI) more or equal to 25 (in $\mathrm{kg} \cdot \mathrm{m}^{-2}$ ) estimated in the first trimester of pregnancy.

The dependent variable was the occurrence of obstetric complication both in antepartum and post partum period.

\subsection{Ethical Consideration}

Ethical clearance was obtained from the University of Cape Coast's Institutional 
Review Board prior to the survey. Anonymity and confidentiality of the collected data were maintained.

\section{Results}

\subsection{Socio-Demographic Characteristics}

Records were reviewed on 510 pregnant women over aone year period. The mean age was 27.8 years with a stardard deviation of 5.1 years, most of the women were between the ages of 20 and 35 years (73.2\%). Majority of these women stopped their education at first (42\%) and second (22\%) cycle schools. Trade was the most common occupation (41\%) and $15.1 \%$ of the mothers were unemployed (Table 1).

\subsection{Obstetric Characteristics of the Study Population}

More than half $(57.9 \%)$ of women had conceived 3 or more times, $23.3 \%$ and $18.8 \%$ are Para 1 and Para 2 respectively. Majority (72.9\%) of the women had spontaneous vaginal delivery while $18.4 \%$ delivered through Caesarean section (Table 2).

Table 1. Socio-demographic characteristics of the study population.

\begin{tabular}{ccc}
\hline Characteristics & Number & Percentage (\%) \\
\hline Age & 53 & \\
$15-19$ & 109 & 10.4 \\
$20-24$ & 161 & 21.4 \\
$25-29$ & 103 & 31.6 \\
$30-34$ & 61 & 20.2 \\
$35-39$ & 20 & 12.0 \\
$40-44$ & 3 & 3.9 \\
45 and above & & 0.6
\end{tabular}

\begin{tabular}{ccc}
\hline Educational Level & 3 & 0.6 \\
None & 30 & 5.9 \\
Primary & 81 & 15.9 \\
JHS/Middle & 214 & 42.0 \\
SHS/Voc & 112 & 22.0 \\
Tertiary & 73 & 14.3 \\
\hline Occupation & & \\
Public/Civil servant & 40 & 7.8 \\
Health worker & 32 & 6.3 \\
Farmer & 14 & 2.7 \\
Trader & 209 & 41.0 \\
Unemployed & 77 & 15.1 \\
Others & 138 & 27.1 \\
\hline
\end{tabular}


Table 2. Obstetric characteristics of the study population.

\begin{tabular}{cc}
\hline Characteristics & Number \\
\hline Gravidity & 96 \\
1 & 119 \\
2 & 295 \\
$\geq 3$ & \\
Parity & 135 \\
0 & 136 \\
1 & 122 \\
2 & 117 \\
\hline 3 & 375 \\
Spontaneous vaginal delivery & 44 \\
Assisted Vaginal delivery & 91 \\
Caesarean section &
\end{tabular}

\subsection{Prevalence of Maternal Obesity}

The prevalence of maternal obesity (overweight/obese, BMI $\geq 25 \mathrm{~kg} / \mathrm{m}^{2}$ ) among women in this survey was estimated at $37.3 \%$ (190/510), with a mean BMI of $43.5 \mathrm{~kg} / \mathrm{m}^{2}$.

\subsection{Risk Factors of Maternal Obesity}

The statistical analysis among those with maternal obesity $(n=190)$ has revealed one year's increase in maternal age accounts for 0.19 increase in mean BMI and this was found to be highly significant $(95 \% \mathrm{CI}=0.08-0.29, \mathrm{p}<0.001)$ and client's parity was also significantly associated with maternal obesity (95\% CI = 1.63 - 5.37, $\mathrm{p}<0.001)$ meaning women who had three or more $(\geq 3)$ live births had a 3.5 increase in mean BMI compared to nulliparous.

How ever there was no significant association between maternal obesity and educational level as well the occupation (Table 3 ).

\subsection{Complications Associated with Maternal Obesity}

Among the 190 maternal obesity cases, 72 of them had complications during the course of the pregnancy and delivery, making a prevalence of $37.9 \%(72 / 190)$, with postpartum hemorrhage (40.3\%), fetal distress (15.3\%) Cephalo-pelvic disproportion (15.2\%) being the top three complications. The caesarian section rate among them was $20.5 \%(39 / 190)$.

Table 4 summarizes the complications found during the study.

\subsection{Maternal Complications in Non-Obese Women}

We found that among the 320 non obese women in our study, only 64 of them had obstetrical complications, making a prevalence of $20 \%(64 / 320)$. 
Table 3. Bivariate linear regression models to explain relationship of maternal obesity between Socio-demographic and Maternal characteristics of women attending antenatal clinic at the Cape Coast Metro Hospital, 2019.

\begin{tabular}{|c|c|c|c|}
\hline \multirow{2}{*}{ Variable } & \multirow{2}{*}{ Level } & \multicolumn{2}{|c|}{ Body Mass Index } \\
\hline & & $\beta(95 \% \mathrm{CI})$ & $\mathrm{p}$-value \\
\hline \multicolumn{4}{|c|}{ Socio-demographic } \\
\hline Age & Age & $0.19(0.08,0.29)$ & $<0.001$ \\
\hline \multicolumn{4}{|c|}{ Educational Level } \\
\hline & No education & Ref. & \\
\hline & Primary & $1.19(-2.01,4.40)$ & 0.465 \\
\hline & JHS/Middle & $0.33(-2.60,3.25)$ & 0.827 \\
\hline & SHS/Vocation & $-0.11(-3.19,2.97)$ & 0.945 \\
\hline & Tertiary & $2.19(-1.06,5.44)$ & 0.186 \\
\hline \multicolumn{4}{|l|}{ Occupation } \\
\hline & Unemployed & Ref. & \\
\hline & Public/Civil servant & $1.91(-1.01,4.83)$ & 0.200 \\
\hline & Health worker & $2.95(-2.21,6.10)$ & 0.067 \\
\hline & Farmer & $1.57(-2.78,5.93)$ & 0.478 \\
\hline & Trader & $2.11(0.11,4.11)$ & 0.038 \\
\hline & Others & $1.12(-1.01,3.26)$ & 0.301 \\
\hline \multicolumn{4}{|l|}{ Parity } \\
\hline & 0 & Ref. & \\
\hline & 1 & $0.44(-1.36,2.24)$ & 0.634 \\
\hline & 2 & $0.83(-1.02,2.68)$ & 0.379 \\
\hline & $\geq 3$ & $3.50(1.63,5.37)$ & $<0.001$ \\
\hline
\end{tabular}

$B$ : coefficient, CI: confidence interval, Ref.: reference or baseline.

Table 4. Various complications among women with maternal obesity attending antenatal clinic at the Cape Coast Metropolitan Hospital, $(n=72)$.

\begin{tabular}{ccc}
\hline Types of complications & Number $(\mathbf{n}=\mathbf{7 2})$ & Frequency (\%) \\
\hline PPH & 29 & 40.3 \\
APH & 5 & 6.9 \\
Eclampsia & 7 & 9.7 \\
CPD & 11 & 15.2 \\
Ruptured uterus & 1 & 1.4 \\
Chorioamnionitis & 2 & 2.8 \\
PROM & 4 & 5.6 \\
Fetal distress & 11 & 15.3 \\
Malpresentation & 2 & 2.8 \\
\hline
\end{tabular}


In comparison with the maternal obesity group, postpartum hemorrhage (32.8\%), fetal distress (12.5\%) Cephalo-pelvic disproportion (10.9\%) was among the common complications. The caesarian section rate among them was $16.2 \%$ $(52 / 320)$.

Table 5 shows the different complication encountered by the non obese women.

\subsection{Relationship between Maternal Obesity and the Occurrence of Its Complications}

In term of prevalence, the statistical analysis showed a significant association between maternal obesity and the occurrence of obstetric complications (Chi-square $=18.6 \mathrm{p}=0.000001)$. Obese pregnant women were more likely to suffer from pregnancy related complications than non-obese pregnant women.

\begin{tabular}{cccc}
\hline \multirow{2}{*}{ MATERNAL OBSEITY } & \multicolumn{2}{c}{ MATERNAL COMPLICATIONS } & \multirow{2}{*}{ TOTAL } \\
\cline { 2 - 3 } & Present & Absent & \\
\hline Present & 72 & 118 & 190 \\
Absent & 64 & 256 & 320 \\
TOTAL & 136 & 374 & 510 \\
\hline
\end{tabular}

\section{Discussion}

\subsection{Limitation}

In our study we could not record the subject's weight changes (gains or losses) during the course of pregnancy, which could have given us more information to do a detailed analysis of the obstetric complications.

\subsection{Prevalence of Obesity among Pregnant Women}

The prevalence of maternal obesity (overweight/obese, BMI $\geq 25 \mathrm{~kg} / \mathrm{m}^{2}$ ) among women in this study was estimated at $37.3 \%$ (190/510). This finding is in line

Table 5. Various complications among non obese women attending antenatal clinic at the Cape Coast Metropolitan Hospital, $(n=64)$.

\begin{tabular}{ccc}
\hline Types of complications & Number $(\mathbf{n}=64)$ & Frequency (\%) \\
\hline PPH & 21 & 32.8 \\
APH & 6 & 9.4 \\
Eclampsia & 7 & 10.9 \\
CPD & 7 & 10.9 \\
Chorioamnionitis & 3 & 4.6 \\
PROM & 6 & 9.3 \\
Fetal distress & 8 & 12.5 \\
Malpresentation & 6 & 9.4
\end{tabular}


with that found in population study by Cheng et al who reported a prevalence of maternal obesity in Africa ranging from 6.5\% to 50.7\% [7]. Several studies also have reported similar high trends of maternal obesity; $48.2 \%$ (31.3\% being overweight and $16.9 \%$ obese) in a cohort study in 1000 women in Accra [8], $46 \%$ among 484 cohort of women in Wales [9], and 17\% - 32\% across 48 states of America in retrospective study [10].

The high prevalence of maternal obesity observed in our study could be linked to unhealthy dietary habits (highly processed food and carbohydrate dominated diet) and the lack of physical activity among our subjects which is termed as obesogenic environment.

\subsection{Common Complications Associated with Pre-Pregnancy Obesity}

In this study, it was observed that $34.4 \%$ of the obese women developed maternal complications, postpartum hemorrhage (42.1\%), obstructed labor (16.7\%), fetal distress (14.4\%), antepartum haemorrhage (9.6\%) and eclampsia (5.7\%) been the top five complications. Similar findings were observed by Van Der Linden et al., (2016) [8] who reported a higher increase in the occurrence of PPH and hypertensive disorders in pregnancy as the BMI increases.

The Caesarian section rate was $20.5 \%$ which is high above the recommend World Health Organization. Higher prevalence of CS among obese women was also recorded in other studies [8] [11].

Maternal obesity has been associated with risk of maternal complications [8] [11] [12], our study is in line with the literature, it was revealed in our survey that maternal obesity is significantly associated with pregnancy related complications $(\mathrm{p}=0.00001)$. Similarly a pregnancy risk assessment and monitoribg system in Maryland (2010) [13], found association between delivery methods, hypertension, diabetes and other complications with maternal obesity in USA. Also, Van Der Linden et al., (2016) [8] in Ghana made similar observation.

\subsection{Risk Factors of Maternal Obesity}

In our survey, there was a significant association between age and higher parity with the presence of maternal obesity with P-values $<0.001$. However the level of education and the occupation were not significantly associated with maternal obesity.

These findings confirmed similar studies in Cape Coast, who report that mean BMI increased with age among women in Central region [14] [15]. Another study in USA also linked pre-pregnancy obesity with age [16]. The mean BMI was higher for women within the ages of $40-44$ years $\left(46.3 \mathrm{~kg} / \mathrm{m}^{2}\right)$ and $25-29$ years $\left(44.9 \mathrm{~kg} / \mathrm{m}^{2}\right)$. Older women are susceptible to weight gain mostly due the change of body metabolism which become slower and reduction of the body muscles being replaced by fat associated with physical inactivity.

It was established that mothers who have had three or more live births were more likely to have 3.5 folds increase in mean BMI compared to mothers who 
have not given birth before $(\mathrm{p}<0.001)$. These confirmed the findings of Amegah (2014), and Tuoyire, Kumi-kyereme, and Doku (2016), who reported a higher BMI among multiparous women compared with nulliparous women. These findings assert to fact that women generally gain weight during pregnancy and those excess kilograms tend to accumulate if the women failed to lose weight after delivery.

Despite the fact that several studies have associated maternal obesity with both education and occupation (Tuoyire et al., 2016; Shen et al., 2018; Stubert, Reister, Hartmann, \& Janni, 2018 [17]; Siega-riz, 2012 [18]), this study observed no association for both education and occupation. This could explained by the fact that most of our subjects didn't have higher education and were mostly traders, making our study population more homogenous in terms of education and occupation.

\section{Conclusions}

The study conducted at the Cape Coast Metropolitan Hospital found a high prevalence of maternal obesity which was common among the older women and those with high parity, however, maternal obesity was not associated with the mother's level of education as well as her occupation.

Obstetric complications were commonly present in obese women and the commonest were postpartum hemorrhage, fetal distress and Cephalo-pelvic disproportion. There was a higher rate of caesarian section in obese mothers compared to normal BMI women.

Although present data was a confirmation of the existing data in other parts of the world, we believe that these data may be useful in making area-specific health policy.

\section{Conflicts of Interest}

The authors declare no conflicts of interest regarding the publication of this paper.

\section{References}

[1] WHO (2020) Obesity and Overweight. https://www.who.int/news-room/fact-sheets/detail/obesity-and-overweight

[2] Ng, M., Fleming, T., Robinson, M., Thomson, B., Graetz, N., Margono, C., et al. (2014) Global, Regional, and National Prevalence of Overweight and Obesity in Children and Adults during 1980-2013: A Systematic Analysis for the Global Burden of Disease Study 2013. The Lancet, 384, 766-781. https://doi.org/10.1016/S0140-6736(14)60460-8

[3] Kim, S.Y., Dietz, P.M., England, L., Morrow, B. and Callaghan, W.M. (2007) Trends in Pre-Pregnancy Obesity in Nine States, 1993-2003. Obesity, 15, 986-993. https://doi.org/10.1038/oby.2007.621

[4] Gaillard, R., Steegers, E.A., Hofman, A. and Jaddoe, V.W. (2011) Associations of Maternal Obesity with Blood Pressure and the Risks of Gestational Hypertensive Disorders. The Generation R Study. Journal of Hypertension, 29, 937-944. 
https://doi.org/10.1097/HJH.0b013e328345500c

[5] Vahratian, A., Zhang, J., Troendle, J.F., Savitz, D.A. and Siega-Riz, A.M. (2004) Maternal Prepregnancy Overweight and Obesity and the Pattern of Labor Progression in Term Nulliparous Women. Obstetrics \& Gynecology, 104, 943-951. https://doi.org/10.1097/01.AOG.0000142713.53197.91

[6] Felisbino-Mendes, M.S., Matozinhos, F.P., Miranda, J.J., Villamor, E. and Velasquez-Melendez, G. (2014) Maternal Obesity and Fetal Deaths: Results from the Brazilian Cross-Sectional Demographic Health Survey, 2006. BMC Pregnancy Childbirth, 14, 5. https://doi.org/10.1186/1471-2393-14-5

[7] Chen, C., Xu, X. and Yan, Y. (2018) Estimated Global Overweight and Obesity Burden in Pregnant Women Based on Panel Data Model. PLoS ONE, 13, e0202183. https://doi.org/10.1371/journal.pone.0202183

[8] Van Der Linden, E.L., Browne, J.L., Vissers, K.M., et al. (2016) Maternal Body Mass Index and Adverse Pregnancy Outcomes: A Ghanaian Cohort Study. Obesity, 24, 215-222. https://doi.org/10.1002/oby.21210

[9] Morgan, K.L., Rahman, M.A., Macey, S., et al. (2014) Obesity in Pregnancy: A Retrospective Prevalence-Based Study on Health Service Utilisation and Costs on the NHS. BMJ Open, 4, e003983. https://doi.org/10.1136/bmjopen-2013-003983

[10] Deputy, N.P., Dub, B. and Sharma, A.J. (2018) Prevalence and Trends in Prepregnancy Normal Weight-48 States, New York City, and District of Columbia, 2011-2015. Morbidity and Mortality Weekly Report, 66, 1402-1407.

https://doi.org/10.15585/mmwr.mm665152a3

[11] Ullah, I., Isabel, D., Sampaio, M., Tamanja, E. and Mensah-bonsu, N.O. (2016) University of Ghana. http://ugspace.ug.edu.gh

[12] Texas Department of State Health Services (2011) Texas Pre-Pregnancy Obesity PRAMS 2009-2011.

[13] Pre-Pregnancy Obesity Maryland 2004-2008 Births. https://health.maryland.gov/phpa/mch/Documents/prams obesity Nov2010.pdf

[14] Amegah, A.K., Lumor, S. and Vidogo, F. (2011) Prevalence and Determinants of Overweight and Obesity in Adult Residents of Cape Coast, Ghana: A Hospital-Based Study. African Journal of Food, Agriculture, Nutrition and Development, 11, 4828-4846. https://doi.org/10.4314/ajfand.v11i3.66635

[15] Tuoyire, D.A., Kumi-kyereme, A. and Doku, D.T. (2016) Socio-Demographic Trends in Overweight and Obesity among Parous and Nulliparous Women in Ghana. BMC Obesity, 3, 44. https://doi.org/10.1186/s40608-016-0124-2

[16] Texas Department of State Health Services (2011) Texas Pre-Pregnancy Obesity Texas Pre-Pregnancy Obesity PRAMS 2009-2011. Texas.

[17] Stubert, J., Reister, F., Hartmann, S. and Janni, W. (2018) The Risks Associated with Obesity in Pregnancy. Deutsches Ärzteblatt International, 115, 276-283. https://doi.org/10.3238/arztebl.2018.0276

[18] Siega-riz, A.M. (2012) Prepregnancy Obesity: Determinants. UNC Gillings School of Global Public Health, Chapel Hill, 105-107.

https://doi.org/10.3945/an.111.001081 